\section{Knowledge of birth defects among nursing mothers in a developing country}

Taiwo Akeem Lawal ${ }^{1}$, Oyindamola Bidemi Yusuf ${ }^{2}$, Akinola Ayoola Fatiregun ${ }^{2}$

1. University of Ibadan, Department of Surgery; University College Hospital, Department of Surgery

2. University of Ibadan, Department of Epidemiology and Medical Statistics

\section{Abstract}

Background: In the absence of established guidelines, where formal screening is unavailable for birth defects, a lot of responsibility is placed on parents in the recognition of these defects.

Objectives: The aim of the study was to determine the awareness of mothers about birth effects in a developing country and assess what they know about the prevention, detection and treatment of children with birth defects.

Methods: This was a descriptive cross-sectional study of 714 mothers consecutively selected at two major hospitals in $\mathrm{Ni}$ geria between May and December, 2012. Data were collected with interviewer administered questionnaires. Descriptive and inferential statistics were performed using SPSS and statistical significance set at $\mathrm{p}<0.05$

Results: The participants were aged 17 to 42 years. Only $183(25.6 \%)$ were aware of birth defects. Factors associated with Results: The participants were aged 17 to 42 years. Only $183(25.6 \%)$ were aware of birth defects. Factors associated with
awareness of birth defects were older age, religious belief, better education, higher socioeconomic class, early age at booking and registering at a tertiary care facility. Education, socioeconomic class as well as month and location of booking were found to be independent predictors of awareness of birth defects.

Conclusion: Mothers in Ibadan, Nigeria, a country without a formal newborn screening programme, have a poor level of awareness about birth defects.

Keywords: Awareness; Mothers; Birth defects; Developing country

DOI: http://dx.doi.org/10.4314/ahs.v15i1.24

Introduction

Routine screening of newborn children for certain birth defects is well established in developed countries, but absent or rudimentary at best in many developing nations. ${ }^{1}$ The major benefits of newborn screening are reductions in neonatal and infant morbidity and mortality through early detection of rare diseases and prompt treatment. ${ }^{2-4}$ It has also led to saved health care costs of billions of dollars in the U.S.A. because of the reduction in the disabilities and debilities associated with delayed diagnosis. ${ }^{4}$ The optimal utilisation of the process of screening, especially for structural anoma-

\section{Corresponding author:}

Taiwo Akeem Lawal

Department of Surgery, University of Ibadan,

PMB 5017, Ibadan 200212, Nigeria.

Tel:+234-8069614811

Email address is: taiwo.lawal@hotmail.com lies, which are easily detected at little or no cost, is only possible if the parents are carried along. ${ }^{5,6}$ In the absence of specific guidelines for screening of newborn children, parents are given a disproportionately higher degree of responsibility in the detection of babies with birth defects.

In many low-middle income countries (LMIC), where these guidelines are relatively unavailable; delay in recognition, delayed presentation to the hospital, delivery outside recognised obstetric care settings and socioeconomic challenges contribute to a higher rate of neonatal mortality. ${ }^{7-9}$ In an attempt to improve primary prevention strategies while pressure is on to encourage the establishment of proper screening programmes, it is imperative to identify target groups for educational enlightenment. There is no information, in the literature, on the perception of parents towards early detection of birth defects or their knowledge about those defects in regions lacking formal screening programs for newborns. The study was thus conducted with the aim of determining the awareness of mothers about birth defects in an LMIC setting without a newborn screening programme.
The study will serve to provide baseline information on the awareness of mothers about birth defects in general. It will, in addition, provide information on the awareness of mothers about the possible prevention, early detection and care of newborns with these defects.

\section{Methods}

Study location

Following ethical approval from the Institution's Ethical Review Committee, a descriptive cross- sectional stud was conducted between May and December, 2012 at the two largest hospitals in Ibadan, Nigeria - the University College Hospital, Ibadan and Adeoyo Maternity Hospital, Yemetu, Ibadan. Ibadan is the largest metropolitan city in Sub-Saharan Africa, with a land mass covering 3,123 square kilometres and an estimated population of over 5 million. The University College Hospital, Ibadan, is an 800 bedded federal government funded hospital with specialists in over 50 different clinical departments and institutes, providing the major source of referral for the care of major debilitating diseases such as congenital malformations in the South-Western part of Nigeria. The Adeoyo Maternity Hospital (AMH) is one of the oldest hospitals for maternal care in Nigeria. The AMH, owned by the state government, is a general hospital with a bias towards maternal and child care. It caters for the teaming population of Ibadan city; with a large proportion from lower socioeconomic groups.

\section{Data collection}

Mothers attending the postnatal immunization clinics of the two hospitals were recruited by consecutively approaching each potential participant and those who consent to participate in the study had a structured interviewer administered questionnaire, to obtain data from them. A total of 760 mothers were approached, out of which $25(3.3 \%)$ were excluded because they were health care workers, $21(2.8 \%)$ declined to participate and $714(93.9 \%)$ completed the study. The questionnaire was translated into the predominant local language (Yoruba) for ease of administration.

Data was collected on sociodemographic variables such as mother's age, marital status, level of education, religion, number of children in the family and other related questions. The occupation was recorded and used to derive the social class based on the Economic and
Social Research Council (ESRC) guidelines and categoised into: Class I - managerial and professional, Class II- intermediate and Class III - working class. ${ }^{10}$ The participants were asked about antenatal details of the (last) pregnancy; whether they attended antenatal clinic for the pregnancy or not - recorded as Yes or No. They were also asked for the location of the antenatal clinic that they attended. The utilization of ultrasound scanning during the pregnancy was assessed by; number of scans performed, if they were told the findings and what the findings were. The mothers' awareness of birth defects was determined using a combination of open and closed ended questions. They were asked if they were aware of birth defects; if the defects could be prevented, detected, inherited or treated; and if they knew that folic acid supplementation could be used to prevent certain birth defects.

\section{Data management}

The mother's age was dichotomised according to the mean, for cross tabulation. Marital status was recorded as single, married or separated. The highest level of education was dichotomised into those with 12 years or less of formal education and those with more than 12 years of formal education. For the purpose of cros tabulation, gravidity was categorised into those who were primigravida and those with more than one previous pregnancy. Parity was dichotomised according to the mean number of children. The location of antenatal care was dichotomised into; tertiary hospital and other hospitals (to include general hospitals, primary health care centres and private clinics).

\section{Statistical analysis}

Data collected was collated, and subjected to statistical analysis using SPSS version 19 and results presented using tables. Categorical data were summarised by frequencies, percentages and proportions, while continuous data were summarised using means, standard deviations, medians and ranges. Tests for association between sociodemographic variables and awareness of birth defects were done using Chi-square statistics. Further bivariate analyses were also done between awareness of birth defects and; the number of children, number of previous pregnancies, number of months of pregnancy when the mother registered for antenatal care and location of antenatal care using Chi-square statistics. 
Significant variables in the bivariate analysis, at an alpha print media, $19(10.4 \%)$, from friends, $17(9.2 \%)$, or of 0.20 , were entered into a binary logistic regression other sources, $35(19.1 \%)$.

model to identify likely predictors of awareness of birth Among the study participants; $113(15.8 \%)$ knew that defects. The outcome variables were: aware of birth de- birth defects could be prevented, $70(9.8 \%)$ knew that fects and not aware of birth defects. All the variables they could be inherited, $111(15.5 \%)$ knew that birth were taken in a single step for the logistic regression. defects could be treated, $68(9.5 \%)$ knew that certain The p-value for statistical significance was set at 0.05 . birth defects could be prevented using folic acid and $95(13.3 \%)$ reported that certain tests could be used to assist in prenatal diagnosis of these defects.

\section{Results}

Sociodemographic and obstetric characteristics Antenatal care visits and counselling about birth A total of 714 mothers participated in the study. They defects

were aged 17 to 42 years with a mean of $29.2( \pm 5.1)$ Each of the participants had between 0 and 6 ultrayears. Most, $695(97.3 \%)$, were married, $364(51.0 \%)$ sound scans performed during the last pregnancy (with participants were Christians and $350(49.0 \%)$ were a median of 2$)$. The majority, $630(88.2 \%)$, was informed Muslims. The majority, $491(68.8 \%)$, of the participants of the findings by the sonographer who performed the were in the working class and $330(46.2 \%)$ had more ultrasound scan examination. A total of $563(78.9 \%)$ than 12 years of formal education.

The participants have had between 1 and 7 pregnancies (with a median of 2 pregnancies). They had 1 to 6 children with a median number of 2 children. The majority, 481 (67.4\%), were multigravida. Most, 671 (94.0\%), of the participants received supervised antenatal care (ANC) for the index pregnancy. The participants registered for antenatal care between the 1 st and 8th months of pregnancy with a mean gestational age at registration of $4.7( \pm 1.5)$ months. A total of 711 participants had between one and eight obstetric ultrasound scans performed, with an average of two.

Awareness of the participants about birth defects Only $183(25.6 \%)$ participants were aware of birth defects. Examples of birth defects given by those who were aware of these anomalies included; Central Nervous System malformations e.g. hydrocephalus and spina bifida, limb anomalies e.g. amelia, congenital talipes equinovarus deformity, congenital heart diseases, craniofacial malformations e.g. cleft lip and palate, choanal atresia and anorectal malformations. The participants who knew about birth defects first heard about this from a doctor or nurse, $47(25.7 \%)$, posters in the hospital, $9(4.9 \%)$, from the mass media, $56(30.6 \%)$, from birth defects and sociodemographic variables.

Table 1 - Socio-demographic variables of the participants and awareness of birth defects

\begin{tabular}{|c|c|c|c|c|c|}
\hline \multirow[b]{2}{*}{$\begin{array}{l}\text { Socio-demographic } \\
\text { variable } \\
\text { Age (years) }\end{array}$} & \multicolumn{3}{|c|}{ Awareness of birth defects } & \multirow[b]{2}{*}{$\chi^{2}$} & \multirow[b]{2}{*}{ p value } \\
\hline & $\begin{array}{l}\text { Aware } \\
\text { No (\%) }\end{array}$ & $\begin{array}{l}\text { Not aware } \\
\text { No }(\%)\end{array}$ & $\begin{array}{l}\text { Total } \\
\text { No (\%) }\end{array}$ & & \\
\hline$\leq 30$ & $95 \quad(21.3)$ & $350(78.7)$ & $445(100.0)$ & 11.362 & $0.001 *$ \\
\hline$>30$ & $88 \quad(32.7)$ & $181(67.3)$ & $269(100.0)$ & & \\
\hline Total & $183(25.6)$ & $531(74.4)$ & $714(100.0)$ & & \\
\hline \multicolumn{6}{|l|}{ Marital status } \\
\hline Single & $3(15.8)$ & $16(84.2)$ & $19(100.0)$ & 0.992 & 0.319 \\
\hline Married & $180(25.9)$ & $515(74.1)$ & $695(100.0)$ & & \\
\hline Total & $183(25.6)$ & $531(74.4)$ & $714(100.0)$ & & \\
\hline \multicolumn{6}{|l|}{ Religion } \\
\hline Christianity & $125(34.3)$ & $239(65.7)$ & $364(100.0)$ & 29.557 & $<0.001 *$ \\
\hline Islam & $58(16.6)$ & $292(83.4)$ & $350(100.0)$ & & \\
\hline Total & $183(25.6)$ & $531(74.4)$ & $714(100.0)$ & & \\
\hline \multicolumn{6}{|l|}{ Education } \\
\hline 12 years or less & $32 \quad(8.3)$ & 352 (91.7) & $384(100.0)$ & 130.000 & $<0.001^{*}$ \\
\hline Over 12 years & $151(45.8)$ & $179(54.2)$ & $330(100.0)$ & & \\
\hline Total & $183(25.6)$ & $531(74.4)$ & $714(100.0)$ & & \\
\hline \multicolumn{6}{|l|}{ Social class } \\
\hline 1 - Managerial & 68 (77.3) & $20 \quad(22.7)$ & $88 \quad(100.0)$ & 169.100 & $<0.001 *$ \\
\hline 2 - Intermediate & $48 \quad(35.8)$ & $86 \quad(64.2)$ & $134(100.0)$ & & \\
\hline 3 - Working class & 66 (13.4) & $425(86.6)$ & $491(100.0)$ & & \\
\hline Total & $183(25.6)$ & $531(74.4)$ & $714(100.0)$ & & \\
\hline
\end{tabular}

*- Statistically significant

Maternal obstetric variables and awareness of birth defects Awareness of birth defects was significantly higher who booked at 5 months or later $36.2 \%$ vs. $17.5 \%$, among participants who booked at tertiary hospitals < 0.001$)$. There were no associations between awarecompared with those who booked at other hospitals ness of birth defects and the number of pregnancies or $(57.3 \%$ vs. $14.7 \%, \mathrm{p}<0.001)$. In addition, birth defect birth to date (Table 2). 
Table 2 - Maternal obstetric variables of the participants and awareness of birth defects

\begin{tabular}{rlllll}
\multicolumn{6}{c}{ Awareness of birth defects } \\
\hline Variable & Aware & Not aware & Total & $\chi^{2}$ & p value \\
& No (\%) & No (\%) & No (\%) & & \\
Gravidity & & & & & \\
Primigravida & $61(26.2)$ & $172(73.8)$ & $233(100.0)$ & 0.055 & 0.855 \\
Multigravida & $122(25.4)$ & $359(74.6)$ & $481(100.0)$ & & \\
Total & $183(25.6)$ & $531(74.4)$ & $714(100.0)$ & & \\
\hline Number of children & $129(27.7)$ & $336(72.3)$ & $465(100.0)$ & 3.119 & 0.077 \\
$\leq 2$ & $54(21.7)$ & $195(78.3)$ & $249(100.0)$ & & \\
Total & $183(25.6)$ & $531(74.4)$ & $714(100.0)$ & & \\
\hline $\begin{array}{c}\text { Location of ANC } \\
\text { Tertiary hospital }\end{array}$ & $106(57.3)$ & $79(42.7)$ & $185(100.0)$ & 131.400 & $<0.001 *$ \\
Other hospital & $77(14.7)$ & $447(85.3)$ & $524(100.0)$ & & \\
Total & $183(25.8)$ & $526(74.2)$ & $709(100.0) * *$ & & \\
\hline GA at booking \\
$<5$ months & $114(36.2)$ & $201(63.8)$ & $315(100.0)$ & 31.891 & $<0.001 *$ \\
$\geq 5$ months & $69(17.5)$ & $325(82.5)$ & $394(100.0)$ & & \\
Total & $183(25.8)$ & $526(74.2)$ & $709(100.0) * *$ & & \\
\hline
\end{tabular}

* - Statistically significant, $* *$ - five participants did not book at all for ANC either at supervised or unsupervised centres, ANC - Antenatal care, GA - Gestational age

Predictors of awareness of birth defects amongst sociodemographic/obstetric variables

Participants who booked for antenatal care at a tertiary hospital were three times more likely to be aware of birth Participants with more than 12 years of formal educa- defects compared to those who booked at other facilition were three times more likely to be aware of birth ties (OR $=3.25,95 \%$ CI: 2.07, 5.10, $\mathrm{p}<0.001$ ). Those defects than those with less education ( $\mathrm{OR}=3.38,95 \%$ who booked for ANC earlier than the fifth month of was nearly six times higher in the managerial and pro- defects as those who booked later in pregnancy $(\mathrm{OR}=$ fessional social class than in the working class $(\mathrm{OR}=1.59,95 \% \mathrm{CI}: 1.04,2.42, \mathrm{p}=0.031)$. The model was $5.75,95 \%$ CI: 2.98, 11.11, $\mathrm{p}<0.001$. bee and religious beliefs were not found to be significant predictors of awareness of birth defects (Table 3).

Table 3 - Logistic regression analysis of relationship between sociodemographic/obstetric variables and awareness of birth defects

\begin{tabular}{lllll}
\hline Variable & Categories of variable & OR & $\mathbf{9 5 \%}$ CI & p value \\
\hline Age group & $>30$ years & 1.056 & $0.659-1.694$ & 0.820 \\
& $\leq 30$ years & & & \\
\hline Religion & Christianity & 1.004 & $0.644-1.565$ & 0.987 \\
& Islam & & & \\
\hline Education & More than 12 years & 3.383 & $1.978-5.788$ & $<0.001^{*}$ \\
received & 12 years or less & & & \\
\hline Social class & 1 - Managerial & 5.747 & $2.976-11.111$ & $<0.001^{*}$ \\
& 2 - Intermediate & 1.319 & $0.779-2.237$ & 0.302 \\
& 3 - Working class & & & \\
\hline Location of & Tertiary hospital & 3.247 & $2.070-5.102$ & $<0.001^{*}$ \\
ANC & Other hospitals & & & \\
\hline GA at & $<5$ months & 1.590 & $1.044-2.421$ & $0.031^{*}$ \\
booking & $\geq 5$ months & & & \\
\hline
\end{tabular}

*Statistically significant, ANC - Antenatal care, GA - Gestational age

\section{Discussion}

The early detection of birth defects, through screening, is associated with prompt treatment, reduction in morbidity and mortality and better survival based on improvement in the quality of life of affected chillien.24 In the absence of well established guidelines for screening of birth defects, such as in Nigeria, a great responsibility is placed on parents who, in addition to the efforts of health care workers, will have to be partners in ensuring early d newborn child. There is no better person that is qualified to detect any of these anomalies that are missed in the immediate newborn period before the child is sent home than a mother who spends the most time with a child at this phase of life. Awareness of birth defects as well as their causes and prevention may also encourage mothers to adopt more positive preventive behaviours.

The present study revealed poor awareness of mothers in the IMIC studied about birth defects as only $25.6 \%$ of the participants were aware of these defects. This proportion is lower than that reported from a focus group discussion conducted on 111 women in the UnitStates concerning knowledge of women (mothers and those planning to be) about Down's syndrome. ${ }^{11}$ In that study all the women had some degree of knowledge about the birth defect that was studied, in a setting where routine screening is periodically conducted for Down's syndrome. This would suggest that awarenes about birth defects may be related to the availability of routine screening programmes.

The predominant sources of information about birth defects for participants who were aware were the mass media and doctors/nurses. This finding is similar to what was reported among Greek mothers in which doctors and the mass media were the major sources of information about birth defects. ${ }^{12}$ Bener et al. ${ }^{13}$ also found that doctors and the print media were the predominant sources of information about the prevention of birth defects in a survey of 1480 Qatari women. The 
mportance of the mass media as a leading source of information about birth defects is probably attributable to the coverage enjoyed by television, radio and the print media as sources of enlightenment and education for the populace with most homes having one form or the other of these. The mass media is also a veritable tool for advertisement of positive behavioural practices such as folic acid intake and discouragement of negative ones that have been implicated in the occurrence of birth defects such as smoking.

An overwhelming majority (94\%) of the participants in the present study registered for antenatal care during the index pregnancy with an obstetrician/midwife in at tendance and performed an average of two ultrasound scans each. This suggests a high level of awareness of the populace about the place of ultrasound scanning in pregnancy. Enakpene et al. ${ }^{14}$ in a survey of 222 women in Ibadan, Nigeria found that women readily of their own volition request for antenatal ultrasound scanning. The major reasons given by the women for presenting for the ultrasound scan in that study were to check for foetal viability $(64.7 \%)$ and to determine the baby's gender $(22.6 \%)$. However, none of the women in that study requested for ultrasound scanning to screen for birth defects in their babies.

The findings on routine obstetric ultrasound scan were explained to $88.2 \% \%$ of the participants by the sonographer in the present study. Furthermore, $78.9 \%$ received explanation about the result of the ultrasound scan from their doctor or midwife. These suggest that the interaction between the women and the sonographer or doctor/midwife is a good source of information about the state of the foetus, i.e. viability, estimating date of delivery and determination of sex. On the other hand, only $4.9 \%$ of the participants in the study received information about birth defects during the antenatal care. Not only does this demonstrate inadequacy of information received from health care workers about screening for birth defects, it also shows the lack of guidelines on information to be made available to expectant mothers. Where those guidelines are in place, parental education by health care workers has been found to be instrumental to the success of newborn screening for birth defects ${ }^{15}$

Participants in the present study were more likely to be aware of birth defects if they; were older than 30 years of age, were Christians, had more than 12 years of formal education or were in the managerial/professional social class. Furthermore, education and social class were found to be significant predictors of awarenes of birth defects. Mavrou et al. ${ }^{12}$ in a study conducted in Greece reported that better awareness of birth defects was noted in older women, those with better education, higher family income and residents of cosmopolitan areas. Lang et al. ${ }^{16}$ similarly found older age and having a college degree to be among predictors of a highe knowledge score of sickle cell disease or cystic fibrosis

in a survey of American women. Other predictors of higher scores in that study were having private health insurance and race. Older age is presumably associated with greater experience of life and the interactions women have with their friends and neighbours may lead to having heard about birth defects in conversations or through other sources. Better educational achievements and being in the upper/middle social classes are likely to expose the women to greater access to the media or internet. The mass media, corroboratively, was found to be the leading source of information about birth defects in the present study.

In this study, participants who booked early (less than five months of gestation) for antenatal care and those that registered at a tertiary hospital were more likely to

be aware of birth defects. Additionally, both variables were found to be predictors of awareness of birth defects. These observations and inferences may be linked to the socioeconomic factors responsible for the choice of facility and time to book for antenatal care. Women of the upper/middle socioeconomic classes are more likely to book at a tertiary hospital or a facility where the quality of care available is above and beyond what obtains in a poorly funded and not so well maintained secondary health care facility. ${ }^{17}$ Oladokun et al. ${ }^{1}$ reported from a cross sectional study of 796 antenatal clinic attendees that early booking in pregnancy is likely to be associated with women who are more educated, professionals and those with fewer previous pregnan-

\section{Conclusion}

The present study has shown that mothers in Ibadan, Nigeria, an LMIC without a formal newborn screening programme, have a poor level of awareness about birth defects. There is a gap in the counselling given to pregnant women attending antenatal care facilities in the setting. Health promotion aimed at prevention, early ness of Anorectal Malformations: A Pointer to Delayed detection and prompt treatment of birth defects can be Diagnosis in a Developing Country. Eur J Pediatr Surg achieved by improving the transmission of information Mar 42013 (Epub ahead of print)

to mothers at antenatal clinics and educating the popu- 9. Lukong CS, Ameh EA, Mshelbwala PM, Jabo BA, lace through mass media and health care workers. The Gomna A, Akiniyi OT, et al. Management of anorechigh degree of awareness and participation in rou- tal malformation: Changing trend over two decades in tine obstetric ultrasonography may be utilized as an Zaria, Nigeria. AfrJ Paediatr Surg 2011; 8(1): 19-22.

advantage in early referral for formal mid-trimester foe- 10. Rose D, O'Reilly K, Martin J. The ESRC review tal anomaly scan, which hitherto had not been available of government social classifications. Population in the region but could now be done at a few centres.

\section{References}

1. Olusanya BO, Solanke OA. Maternal and neonata factors associated with mode of delivery under a universal newborn hearing screening programme in Lagos, Nigeria. BMC Pregnancy Childbirth 2009; 9: 41.

2. American Academy of Pediatrics Task Force on

Newborn Screening. Serving the family from birth to the medical home. A report from the Newborn Screening Task Force convened in Washington DC, May 1011, 1999. Pediatrics 2000; 106(2 Pt 2): 383-427.

3. Fant KE, Clark SJ, Kemper AR. Completeness and complexity of information available to parents from newborn-screening programs. Pediatrics 2005; 115(5): 1268-1272.

4. Hoffman GL, Laessig RH. Screening newborns for congenital disorders. WMJ 2003; 102(6): 45-50.

5. Aite L, Zaccara A, Trucchi A, Nahom A, Iacobelli B, Bagolan P. Parents' informational needs at the birth of a baby with a surgically correctable anomaly. Pediatr Surg Int 2006; 22(3): 267-270

6. Arnold CL, Davis TC, Frempong JO, Humiston SG, Bocchini A, Kennen EM, et al. Assessment of newborn screening parent education materials. Pediatrics 2006; $117(5$ Pt 2): S320-325.

7. Ademuyiwa AO, Sowande OA, Ijaduola TK, Adejuyigbe O. Determinants of mortality in neonatal intestina obstruction in Ile Ife, Nigeria. Afr I Paediatr Surg 2009; 6(1): 11-13

8. Lawal TA, Fatiregun AA, Yusuf OB. Mothers' Aware-
Trends-London 1997: 49-56.

11. Levis DM, Harris S, Whitehead N, Moultrie R, Duwe $\mathrm{K}$, Rasmussen SA. Women's knowledge, attitudes, and beliefs about Down syndrome: a qualitative research study. Am J Med Genet A 2012; 158A(6): 1355-1362.

2. Mavrou A, Metaxotou C, Trichopoulos D. Awareness and use of prenatal diagnosis among Greek womn: a national survey. Prenat Diagn 1998; 18(4): 349-

3. Bener A, Al Maadid MG, Al-Bast DA, Al-Marri S. Maternal knowledge, attitude and practice on folic acid intake among Arabian Qatari women. Reproductive toxicology 2006; 21(1): 21-25.

4. Enakpene CA, Morhason-Bello IO, Marinho AO, Adedokun BO, Sogo K, Gbadamosi SA, et al. Clients' reasons for prenatal ultrasonography in Ibadan, South West of Nigeria. BMC Womens Health 2009; 9: 12. 15. Kim S, Lloyd-Puryear MA, Tonniges TF. Examination of the communication practices between state newborn screening programs and the medical home.

16. Lang CW, Stark AP, Acharya K, Ross LF. Maternal knowledge and attitudes about newborn screening for sickle cell disease and cystic fibrosis. Am J Med Genet A 2009; 149A(11): 2424-2429.

17. Iyaniwura CA, Yussuf Q. Utilization of antenatal care and delivery services in Sagamu, south western $\mathrm{Ni}$ geria. Afr J Reprod Health 2009; 13(3): 111-122.

18. Oladokun A, Oladokun RE, Morhason-Bello I, Belo AF, Adedokun B. Proximate predictors of early antenatal registration among Nigerian pregnant women. Ann Afr Med 2010; 9(4): 222-225. Pediatrics 2003; 111(2): E120-126. 